\title{
Electricity vs Ecosystems - understanding and predicting hydropower impact on Swedish river flow
}

\author{
BERIT ARHEIMER \& GÖRAN LINDSTRÖM \\ Swedish Meteorological and Hydrological Institute (SMHI), 60176 Norrköping, Sweden \\ Berit.Arheimer@smhi.se
}

\begin{abstract}
The most radical anthropogenic impact on water systems in Sweden originates from the years 1900-1970, when the electricity network was developed in the country and almost all rivers were regulated. The construction of dams and changes in water flow caused problems for ecosystems. Therefore, when implementing the EU Water Framework Directive (WFD) hydro-morphological indicators and targets were developed for rivers and lakes to achieve good ecological potential. The hydrological regime is one such indicator. To understand the change in flow regime we quantified the hydropower impact on river flow across Sweden by using the S-HYPE model and observations. The results show that the average redistribution of water during a year due to regulation is $19 \%$ for the total discharge from Sweden. A distinct impact was found in seasonal flow patterns and flow duration curves. Moreover, we quantified the model skills in predicting hydropower impact on flow. The median NSE for simulating change in flow regime was 0.71 for eight dams studied. Results from the spatially distributed model are available for 37000 sub-basins across the country, and will be used by the Swedish water authorities for reporting hydro-morphological indicators to the EU and for guiding the allocation of river restoration measures.
\end{abstract}

Key words hydrological regime; change; regulation; dams; naturalized, model skills; multi-basin; S-HYPE

\section{INTRODUCTION}

There is a growing interest among hydrological scientists in how society and water systems are coevolving (Wagener et al. 2010, Sivapalan et al. 2012, Montanari et al. 2013) as it is important to find a balance between water for humans and water for nature (Falkenmark and Rockström 2004) and efficient methods for integrated water management (Rahaman and Varis 2005).

Dysenius and Nilsson (1994) found out that $77 \%$ of the river discharge from the northern part of the world is affected by fragmentation of the river channels by dams and water regulation. Sweden is an example of this, being a country in northern Europe and rich in surface water, which has been used by humans since the start of civilization. The most radical anthropogenic impact on water systems in Sweden remains from the years 1900-1970, when the electricity network was developed in the country, exploiting the potential energy of surface water. Lakes and rivers became regulated as numerous dams were constructed, especially in the north, to meet the societal needs of electricity for railways, industries and households. The hydropower development was a major contribution to the industrialization of Sweden and amounts today to half of the electricity supply for the country. There are $\sim 1800$ hydropower plants in Sweden, out of which some 200 produce $>10 \mathrm{MW}$, providing $94 \%$ of the production. The total annual production varies from 50 to $75 \mathrm{TWh}$ due to water recharge, with an average of $65 \mathrm{TWh} /$ year. River flow in Sweden is highest during spring, but winters in Sweden are long, cold and dark; therefore there is a need for storing water from spring and summer for hydroelectric production in the autumn and winter.

The environmental problems linked to hydropower were recognized during the 1960s and are today considered as the major causes of aquatic ecosystem degradation in Sweden (HaV 2013) and heavily modified waterbodies in Europe (EEA 2012, Künitzer 2013). Hydropower has negative effects on fish, biodiversity, water quality and landscape, as it creates dry river channels, flow obstacles, changed flow patterns and short-term fluctuation of water level (e.g. Andersson et al. 2000, Bunn and Arthington 2002, Leira and Cantonati 2008). The EU Water Framework Directive (WFD) therefore demands regular reporting on the level of hydro-morphological alterations for all water bodies (EEA 2012) and that hydro-morphological pressures should be reduced (Künitzer 2013). To improve the situation, the Swedish Water Authorities have recently introduced three new hydro-morphological indicators for monitoring: (i) hydrological regime, (ii) morphological status, and (iii) connectivity between waterbodies ( $\mathrm{HaV}$ 2013). In addition, they recommend the DHMS method (Black et al. 2005) for classifying the risk of damage to in-stream ecology 
(Näslund et al. 2013). This method uses time-series of both regulated and unregulated conditions, which may be difficult to retrieve. SMHI was asked to provide such time-series to the Swedish water authorities, and in addition, to estimate baseflow indices, volume and degree of regulation, change in storage volume and flow. This information is needed for the new WFD indicators and for efficient allocation of measures to achieve good ecological potential.

To meet these requests, a general method to predict river regulation by hydropower was validated. The method is part of the national multi-basin model system covering Sweden, called S-HYPE (Strömqvist et al. 2012). Thereafter, a method to simulate natural conditions was tested and applied for all major dams in Sweden. The scientific questions asked in this paper are: (1) what is the total change in river-flow regime for Sweden due to hydropower production? and, (2) what are the skills in predicting hydropower impact on flow regimes, using a conceptual model approach?

\section{DATA AND METHODS}

Figure 1 shows the degree of flow regulation in Sweden, as modelled in the S-HYPE model. The impact of regulation for hydropower production was estimated using the S-HYPE model with routines to predict river regulation and naturalized flow, respectively. Model runs including and excluding the regulation in terms of hydropower dams were done for the period 1981-2010 to evaluate effects on river flow regarding seasonality, annual high flow, and flow duration. The model routine for regulation was evaluated by comparing modelled and observed daily time-series from the national monitoring network, using 201 gauges in regulated rivers. The model approach for naturalized flow was evaluated after eight hydropower dams (Fig. 1) by comparing modelled river discharge with independent reconstructions based exclusively on observations. For these dams, the hydropower companies have reconstructed the naturalized flow based on measurements of discharge and lake-water levels, which does not involve any hydrological modelling. They are thus estimated in an independent way compared to the model-based study presented in this paper. The observed reconstructions were used to test the skills of the model to predict naturalized nonregulated conditions.

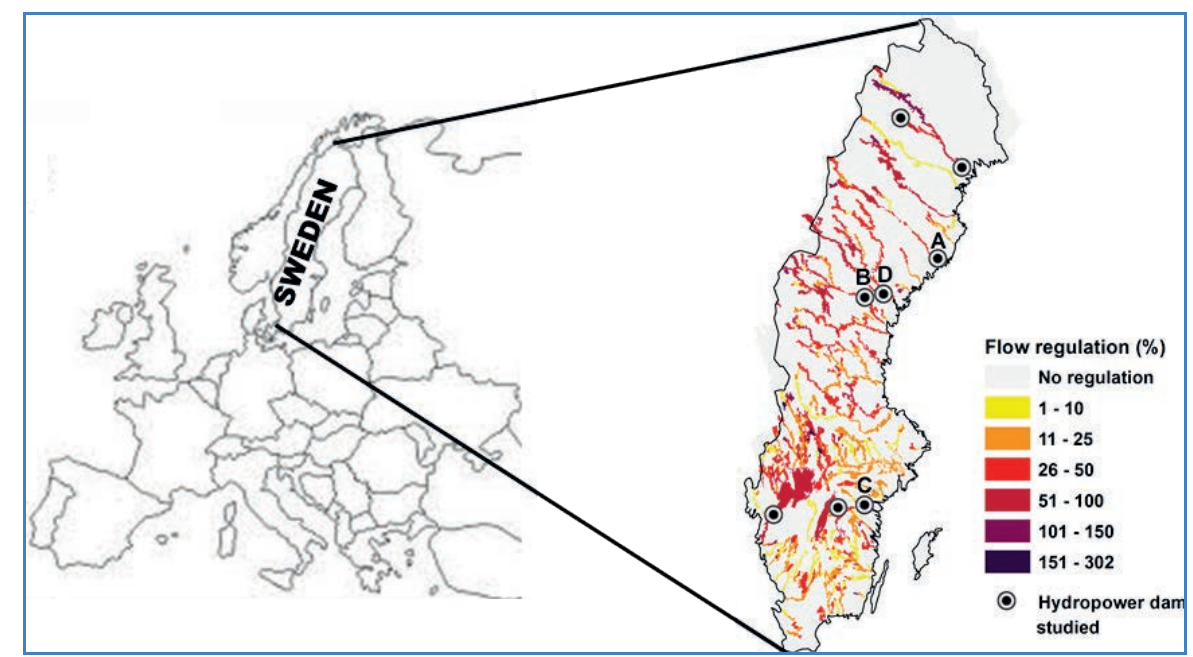

Fig. 1 Map showing degree of up-stream flow regulation of annual water-discharge volume in Swedish rivers. The eight hydropower dams studied in greater detail are marked, and letters refer to illustrated results below (Figs 3-4).

\section{The S-HYPE model}

S-HYPE is a national multi-basin model system for Sweden that covers more than $450000 \mathrm{~km}^{2}$ and produces daily values of hydrological variables in 37000 catchments from 1961 onwards. It is based on the conceptual, processed-based and semi-distributed HYdrological Predictions for the Environment (HYPE) code (Lindström et al. 2010). The S-HYPE application (Strömqvist et al. 
2012) covers the Swedish landmass, including transboundary river basins with Norway and Finland. The first national model-system was launched in 2008, but S-HYPE is continuously improved and released in new versions every second year. Most catchments are ungauged, but observations are available in 400 sites for model evaluation of daily water discharge. A number of model-performance criteria are estimated in each site, e.g. the Nash and Sutcliffe (1970) Efficiency (NSE). The latest S-HYPE version (2012) has an average NSE $=0.81$ for 200 stations unaffected by regulation and an average relative volume error of $\pm 5 \%$ for the period 1999-2008. For all 400 sites, including both regulated and unregulated rivers, average NSE $=0.70$. Average NSE includes catchments ranging from a few to several tens of thousands of $\mathrm{km}^{2}$ and various landuses across the country. The S-HYPE model is assumed to be also valid for ungauged basins, which has been validated in blind tests for independent gauges, resulting in similar values as in calibrated ones for groups of similar catchments (Arheimer and Lindström 2013). The S-HYPE model provides different kinds of water information and open data to Swedish water authorities and the public, free to download from the web site: http://vattenweb/.

\section{Method to predict regulated flow, QR}

The S-HYPE model includes 509 regulated lakes and reservoirs, and 23 man-made river diversions leading water over catchment boarders. Each regulated reservoir or group of reservoirs is treated separately, with individual storage volumes as input data. The model simulates the alteration of river flow in a conceptual way by water storage from spring and summer to hydropower production during autumn and winter. The seasonal production pattern is estimated individually from observations of discharge and water levels. This was done explicitly for some 50 gauged dams, and group-wise for some 400 lakes and reservoirs upstream of rivergauges. Some small dams are modelled by using a general regulation routine. The function of the regulation routine is that: (i) when the water level is low production is reduced, (ii) at moderate water levels the outflow only depends on the time of the year, (iii) when a dam is nearly full, discharge occurs through the spillways. The spillway flow is modelled by a rating curve, which is calibrated separately using the same observations as when estimating the seasonal production.

\section{Method to predict non-regulated and naturalized flow, QN}

The S-HYPE model has 9082 non-regulated lakes explicitly modelled at sub-basin outlets. Lake routing is modelled by establishing rating curves from observed discharge and lake-water levels. These are either explicitly determined from observations (from various time-periods) in individual lakes, calibrated group-wise using downstream gauges or for regions, or by using a general rating curve. When simulating non-regulated conditions, assumptions about such natural rating curves must be made for sites with lake regulation today. For 30 major reservoirs a specific rating curve was established to describe naturalized flow based on measurements of water discharge and lake level fluctuations, either by observations prior to regulations or by using the rating curve from reconstructions of present time. For the 476 remaining lakes the estimated spill equations for the spillways were used. Naturalized flow was then modelled by using the new rating curves and removing all regulation storages and man-made diversions in the model. Three man-made lakes were removed completely and replaced with forest on till soil. The daily effect $(\Delta Q)$ of hydropower impact on river flow was estimated as:

$$
\Delta \mathrm{Q}(\mathrm{t})=\mathrm{QR}(\mathrm{t})-\mathrm{QN}(\mathrm{t})
$$

\section{RESULTS AND DISCUSSION}

According to the model results for the whole of Sweden, hydropower has a significant impact on the seasonal distribution of flow, as water is stored during the high flow of the snow-melt and released during winter when electricity is needed most (Fig. 2). This is according to expectations, since the purpose of regulation is to store water from one time period to another. For the whole 
country, and for an average year, the average deviation between regulated and naturalized flow, i.e. the average redistribution of water during a year due to regulation, was estimated as $19 \%$. Accordingly, the mean annual maximum flow was found to be reduced by $15 \%$. The flow duration curve also shifts towards less difference between high and low flow for regulated conditions, and this can also be noted in the continuous time-series of river flow discharge. Figure 2 shows the shift in water dynamics aggregated for the entire nation, but in addition, similar time-series of present and naturalized flow are available for each of the 37000 sub-basins in the S-HYPE model.

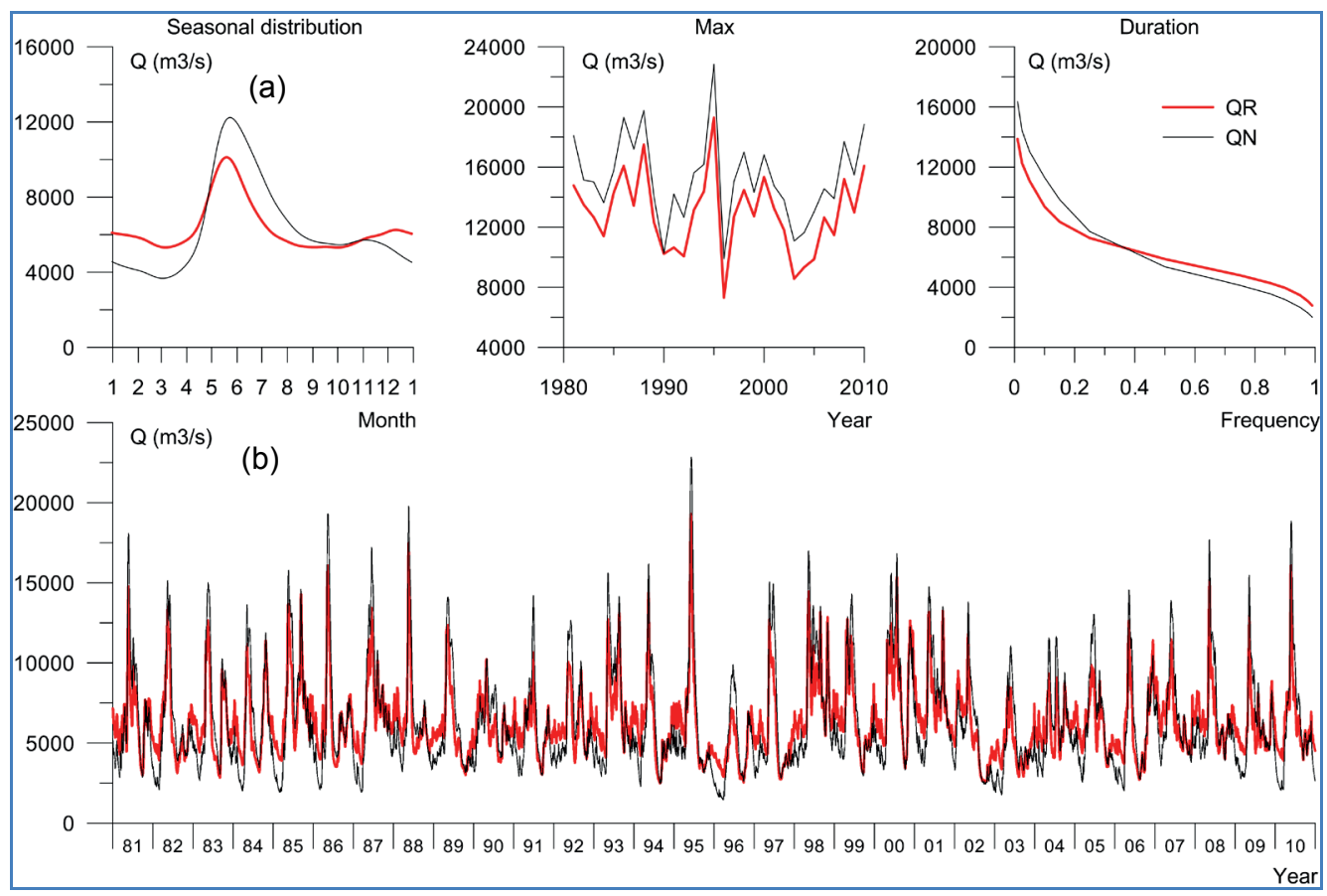

Fig. 2 (a) simulated average seasonal distribution, annual maximum, and flow duration for regulated and naturalized conditions, respectively, for total river-discharge from Sweden. QR = modelled river flow including regulation; QN = naturalized flow, both from HYPE simulations. (b) daily time-series of the modelled period 1981-2010, with and without regulation.

When evaluating the method for predicting impact from hydropower, the routine of flow regulation in S-HYPE resulted in NSE $=0.60$ for the 201 gauges for regulated rivers. This is considered as rather good results for regulated rivers as dam regulation is often short-term, reflecting daily needs, prices and supply which affect the model ability. One extreme influence of this daily regulation is, e.g. found for Lennartsfors (Upperudsälven River) where the NSE shifted from 0.47 to 0.80 when applying a modelled 7-days weighted average instead of daily values in the NSE calculation. For the eight hydropower plants explicitly studied, the modelling resulted in a median daily NSE-value for river flow on 0.66 (Table 1). The value of performance was related to degree of regulation and upstream lake area. The sites with high flow regulation showed low NSE values and poor skills were also noted at the outlet of Lake Vättern (Motala), which is a very large lake compared to the drainage basin that feeds the river. The dampning of the hydrograph, higher influence of evaporation, and long-term fluctuations in lake water make it more difficult to reach a high NSE at the outlet.

In addition, the outflow of Lake Vättern is more affected by short-term regulation than by seasonal re-distribution of the flow, which also makes it difficult to reproduce using the model. The HYPE modelling for naturalized flow shows good agreement with the more detailed reconstructions based on observed water levels (Table 1). All stations showed NSE of more than 0.7 , except the highly regulated Seitevare, which has a rather small drainage basin and $85 \%$ flow regulation with intense short-term fluctuations. Finally, when explicitly testing the model predictability of hydropower impact, by studying the effect itself in the HYPE-model compared to 
Table 1 S-HYPE model performance (NSE) at the eight hydropower plants using daily values for river flow including regulation ( $Q R)$ tested against observations; for naturalized conditions (QN) tested against independent reconstruction; and for the hydropower impact $(\Delta Q)$ tested against observations combined with independent reconstructions.

\begin{tabular}{llllllll}
\hline River & $\begin{array}{l}\text { Hydropower } \\
\text { plant (dam) }\end{array}$ & $\begin{array}{l}\text { Recharge } \\
\text { area }\left(\mathrm{km}^{2}\right)\end{array}$ & $\begin{array}{l}\text { Upstream } \\
\text { lakes }(\%)\end{array}$ & $\begin{array}{l}\text { Flow } \\
\text { regulation } \\
(\%)\end{array}$ & $\begin{array}{l}\text { NSE } \\
\text { QR }\end{array}$ & $\begin{array}{l}\text { NSE } \\
\text { QN }\end{array}$ & $\begin{array}{l}\text { NSE } \\
\Delta Q\end{array}$ \\
\hline Luleälven & Seitevare & 2250 & 7 & 85 & 0.29 & 0.64 & 0.69 \\
Luleälven & Boden & 24924 & 9 & 67 & 0.07 & 0.88 & 0.76 \\
Umeälven & Stornorrfors & 26568 & 8 & 25 & 0.82 & 0.93 & 0.73 \\
Angermanälven & Sollefteå & 30638 & 9 & 37 & 0.70 & 0.91 & 0.86 \\
Indalsälven & Hammarforsen & 23842 & 10 & 39 & 0.63 & 0.90 & 0.84 \\
Motalaström & Motala & 6384 & 35 & 65 & 0.31 & 0.71 & 0.14 \\
Motalaström & Holmen & 15384 & 21 & 41 & 0.79 & 0.89 & 0.09 \\
Göta älv & Vargön & 46886 & 19 & 74 & 0.70 & 0.91 & 0.46 \\
Average & & & & & 0.54 & 0.85 & 0.57 \\
Median & & & & & 0.66 & 0.90 & 0.71 \\
\hline
\end{tabular}

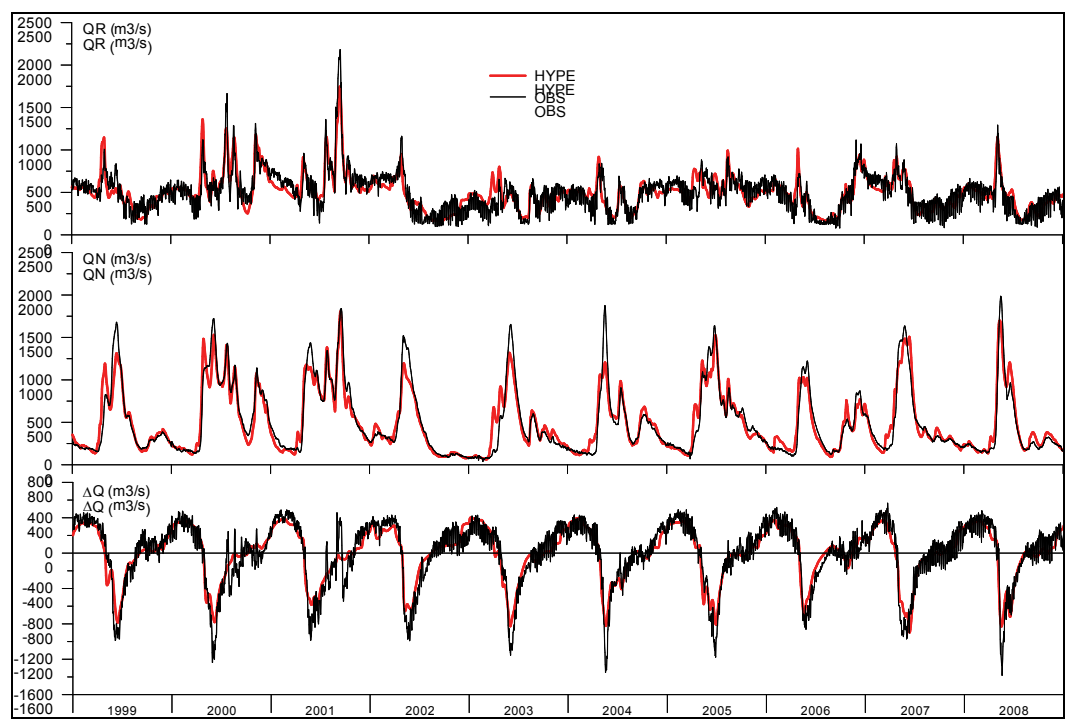

Fig. 3 Time-series of S-HYPE model performance at Sollefteå hydropower plant (D in Fig 1). Top: Simulated and observed water flow including regulation. Middle: simulated naturalized flow and independent reconstruction. Bottom: Simulated impact of hydropower plant on river flow, using SHYPE and observations combined with independent reconstruction, respectively.

observations $v s$ reconstruction, there was normally a good agreement with a median NSE of 0.71 . Again, lower performance was noted for the sites with large upstream lakes.

Figure 3 shows time-series to further illustrate the three different methods used for evaluating the model predictions of hydropower impact on river flow in Ångermanälven River. This is one of the more complex regulated rivers with many coupled hydropower dams along the river network. Nevertheless, it is representative for the overall model performance of regulated river flow in SHYPE. The upper graph highlights the influence of short-term regulation, which typically gives a very irregular hydrograph $(\mathrm{QR})$. The model is not capable of fitting these daily fluctuations, but only the general flow pattern. The second graph indicates that the S-HYPE routine for reconstructing naturalized river flow $(\mathrm{QN})$ is very similar to the independent reconstructions made by the hydropower companies. The final graph shows that the actual hydropower impact $(\Delta \mathrm{Q})$ on daily river flow of Ångermanälven varies between increasing the flow by $400 \mathrm{~m}^{3} / \mathrm{s}$ or by storing up to $800-1200 \mathrm{~m}^{3} / \mathrm{s}$ during the spring flood. Overall, S-HYPE simulations are very similar to estimates using observed and reconstructed values, although the daily short term fluctuations are not captured.

In addition to statistical criteria, the difference in model performance for various sites is also recognised when plotting the seasonal dynamics during an average year or the flow duration curves 
(Fig. 4). The graphs of Motala ström clearly shows the influnce by numerous lakes in the river system and the impact of hydropower is less pronounced than for the northern rivers. In the northern rivers, where the degree of regulation is $25 \%$ at Stornorrfors in Umeälven River and $39 \%$ at Hammarforsen in the Indalsälven River, the graphs clearly show the removal of the distinct natural spring-peak $(\mathrm{QN})$ by regulation $(\mathrm{QR})$ and storage of water in the dams. Accordingly, the winter flow is considerably higher for regulated flow due to hydropower production than for naturalized conditions. Also the flow duration curves show similar patterns for the specific rivers as for the whole country (cf. Fig. 2) with less pronounced extremes in high and low flow due to hydropower regulation. The hydropower impact is very similar when comparing graphs for observations and reconstruction with the S-HYPE model approach (Fig. 4). The flow duration curve of Motala ström diverge between modelled and observed flow frequency of low flows; this is probably an effect of the short-term regulation, which is diffcult to capture and not yet included in the HYPE model.
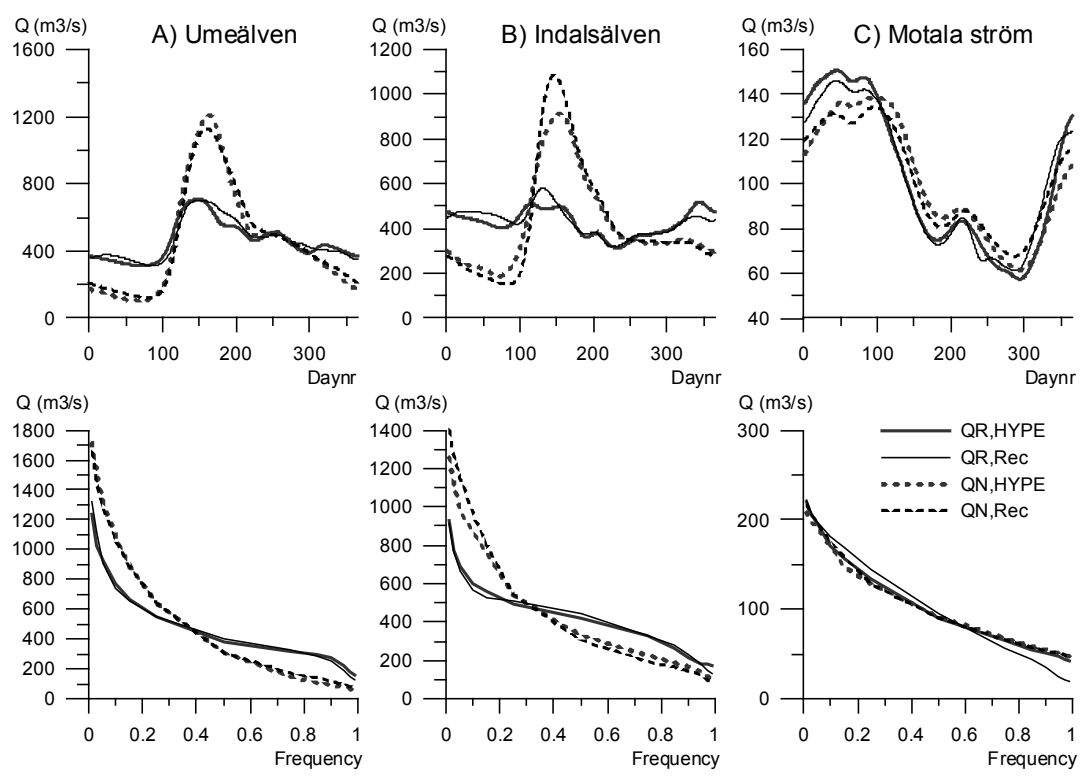

Fig. 4 River flow during regulated (QR, solid lines) and naturalized (QN, dotted lines) conditions at three hydropower plants across Sweden (cf. Fig 1), using the S-HYPE model and independent reconstructions, respectively. On top: Average daily water discharge during a general year. Bottom: Flow duration curves.

\section{Final remarks}

The hydrological community is increasingly required to advocate sustainable development, by further evolving water-resources awareness and management into the future (Rahaman and Varis 2005, Montanari et al. 2013). The presented study shows how hydrological modelling can contribute to sustainable water management and improved ecological potential. The model results for each of the 37000 sub-basins have been released to the Swedish water authorities and the public on the internet for free downloading at http://vattenweb/. In Swedish WFD-work the modelled data will be used for: (i) risk classification (according to DHRAM), (ii) monitoring with the new hydro-morphological indices, and (iii) measure plans to allocate resources for ecosystem restoration to sites with best prospects for recovery. Measures to achieve good environmental potential in regulated rivers include, e.g. fish ladders, bypass channels, habitat restoration, sediment/debris management, minimum ecological flow, removal of structures, operational modifications for hydro-peaking, reconnection of meander bends, and restoration of bank structure (European Commission 2012, Künitzer 2013).

The modelled information will thus be used for local analysis of hydropower impact on flow in specific lakes and river reaches. Other methods for estimating impact of river regulation could be to analyse observed time-series before and after regulation, where such are available, or by lumped modelling calibrated for historic periods (e.g. Carlsson and Sanner 1996). Some advantages of using 
the more detailed model approach presented in this study are that: (i) it covers the whole country with high spatial resolution, (ii) is validated against independent data in specific dams, (iii) takes into account flow variability caused by weather effects, and (iv) can be used for scenario experiments, also combined with other changes in the catchment. The new detailed model approach (S-HYPE) is partly an offspring of the long-term scientific initiative on predictions in un-gauged basins (Bloeschl et al. 2013). Hence, the study is a good example of the two ways interaction between water and society, and how hydrological sciences and water management co-evolve over time.

\section{CONCLUSIONS}

Hydropower production has changed the total river-flow regime in Sweden: The average redistribution of water during a year is $19 \%$ due to regulation for the whole country (including both regulated and non-regulated rivers); The distinct natural spring peak flow caused by snow melt has diminished by $15 \%$ due to storage of water in the dams and the winter flow has become considerably higher due to hydropower production. Accordingly, the flow duration curves show less pronounced extremes in high and low flow due to regulation. The S-HYPE model has skills to predict hydropower impact: The predictions agree well with observations at the local scale as well as independent reconstructions based on observed flow and lake level fluctuations. The median NSE for modelled change in hydrological regime was 0.71 for eight dams studied explicitly.

\section{REFERENCES}

Andersson, E., Nilsson, C. and Johansson, M. E. (2000) Effects of river fragmentation on plant dispersal and riparian flora. Regulated Rivers: Research and Management 16, 83-89.

Arheimer, B. and Lindström, L. (2013) Implementing the EU Water Framework Directive in Sweden. Chapter 11.20. In: Runoff Predictions in Ungauged Basins - Synthesis across Processes, Places and Scales (ed. by G. Bloeschl et al.). Cambridge University Press, Cambridge, UK. (p. 465) pp. 353-359.

Black, A. R., et al. (2005) DHRAM: a method for classifying river flow regimes for the EC Water Framework Directive. Aquatic conservation: Marine and Freshwater Ecosystems 15, 427-446.

Bloeschl, G., et al. (eds) (2013) Runoff Predictions in Ungauged Basins - Synthesis across Processes, Places and Scales. Cambridge University Press, Cambridge, UK. (p. 465)

Bunn, S. E. and Arthington. A. H. (2002) Basic principles and ecological consequences of altered flow regimes for aquatic biodiversity. Environmental Management 30, 492-507.

Dysenius, M. and Nilsson, C. (1994) Fragmentation and flow regulation of river systems in the northern third of the world. Science 266, 753-762.

European Commission (2012) Commission staff working document, European overview, Accompanying the document Report from the Commission to the European parliament and the Council on the Implementation of the Water Framework Directive (2000/60/EC) River Basin Management Plans. 257 p.

EEA (2012) European waters - assessment of status and pressures. European Environment Agency. Office for Official Publications of the European Union, Luxembourg, $100 \mathrm{p}$.

Falkenmark, M. and Rockström, J. (2004) Balancing Water for Humans and Nature: The New Approach in Ecohydrology. Earthscan, $247 \mathrm{p}$.

HaV (2013) Sötvatten 2013 - om miljötillståndet i Sveriges sjöar och vattendrag. Swedish Agency for Marine and Water Management, Report. 56 p. ISBN: 978-91-87025-31-0 (in Swedish).

Leira, M. and Cantonati, M. (2008) Effects of water-level fluctuations on lakes: an annotated Bibliography. Hydrobiologia 613, $171-184$.

Lindström, G., et al. (2010) Development and test of the HYPE (Hydrological Predictions for the Environment) model - A water quality model for different spatial scales. Hydrology Research 41(3-4), 295-319.

Künitzer, A. (2013) Pan-European information needs on quality of freshwater. In: Understanding Freshwater Quality Problems in a Changing World (ed. by B. Arheimer et al.). IAHS Publ. 361, 39-48. IAHS Press, Wallingford, UK.

Montanari, A., et al. (2013) "Panta Rhei-Everything Flows": Change in hydrology and society-The IAHS Scientific Decade 2013-2022. Hydrological Sciences Journal 58(6), 1256-1275.

Nash, J. E. and Sutcliffe, J. V. (1970) River flow forecasting through conceptual models. Part I. A discussion of principles. J. Hydrol. 10, 282-290.

Näslund, I., Kling, J. and Bergengren, J. (2013) Vattenkraftens påverkan på akvatiska ekosystem - en litteratursammanställning. Swedish Agency for Marine and Water Management, Report no. 2013:10. 77 p. ISBN 9789187025-35-8 (in Swedish)

Rahaman M. and Varis, O. (2005) Integrated water resources management: evolution, prospects and future challenges. Sustainability: Science, Practice, and Policy 1, 15-21.

Sivapalan, M., Savenije, H. H. G., and Blöschl, G. (2012) Sociohydrology: a new science of people and water. Hydrological Processes 26, 1270-1276.

Strömqvist, J., et al. (2012) Water and nutrient predictions in ungauged basins - Set-up and evaluation of a model at the national scale. Hydrological Sciences Journal 57(2), 229-247.

Wagener, T., et al. (2010) The future of hydrology: an evolving science for a changing world. Water Resources Research 46(5), W05301. 